$\stackrel{W}{=}$

Global burnals Inc.

है

GLOBAL JOURNAL OF MEDICAL RESEARCH: E

GYNECOLOGY AND OBSTETRICS

Volume 20 Issue 3 Version 1.0 Year 2020

Type: Double Blind Peer Reviewed International Research Journal

Publisher: Global Journals

Online ISSN: 2249-4618 \& Print ISSN: 0975-5888

\title{
Renal Angiomyolipoma during Pregnancy: A Case Report
}

\section{By Atoui Hadi, El Haddad Cynthia, Barakat Habib \& Darido Jessie \\ Holy Spirit University of Kaslik}

Abstract- Renal angiomyolipoma (AML) is the most common benign tumor of the kidney. There are few case reports in the literature, especially those occurring during pregnancy.

We, at this moment, are reporting a case of a 32-year-old female patient who presented at 21 weeks of gestation with right-sided flank pain, chills, macroscopic hematuria, and vomiting. On examination, she was hemodynamically stable, with no fever. Renal ultrasound showed the presence of a hyperechogenic vascularized fatty tissue on the right kidney, measuring $7.4 \times 5.1 \times$ $6.2 \mathrm{cms}$, with minimal pelvicalyceal dilatation. The MRI opted for an angiomyolipoma. Discharged home at day 4 of admission, the patient's continued the remaining weeks of her pregnancy uneventfully, until 37 weeks. She delivered her baby vaginally with no further complications during pregnancy or in the post-partum period.

In conclusion, due to the insufficient data in the literature supporting the management of patients with AML, the individualization of the treatment is an essential strategy.

Keywords: "angiomyolipoma" "renal tumor" "pregnancy" "surgery" "embolization".

GJMR-E Classification: NLMC Code: WJ 190

Strictly as per the compliance and regulations of:

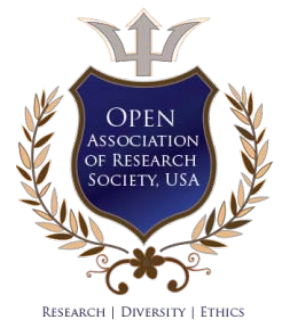

(c) 2020. Atoui Hadi, El Haddad Cynthia, Barakat Habib \& Darido Jessie. This is a research/review paper, distributed under the terms of the Creative Commons Attribution-Noncommercial 3.0 Unported License http://creativecommons.org/licenses/by$\mathrm{nc} / 3.0 /$ ), permitting all non-commercial use, distribution, and reproduction in any medium, provided the original work is properly cited. 


\title{
Renal Angiomyolipoma during Pregnancy: A Case Report
}

\author{
Atoui Hadi ${ }^{\alpha}$, El Haddad Cynthia ${ }^{\sigma}$, Barakat Habib $^{\rho}$ \& Darido Jessie ${ }^{\omega}$
}

Abstract- Renal angiomyolipoma (AML) is the most common benign tumor of the kidney. There are few case reports in the literature, especially those occurring during pregnancy.

We, at this moment, are reporting a case of a 32year-old female patient who presented at 21 weeks of gestation with right-sided flank pain, chills, macroscopic hematuria, and vomiting. On examination, she was hemodynamically stable, with no fever. Renal ultrasound showed the presence of a hyperechogenic vascularized fatty tissue on the right kidney, measuring $7.4 \times 5.1 \times 6.2 \mathrm{cms}$, with minimal pelvicalyceal ${ }^{* 1}$ dilatation. The MRI opted for an angiomyolipoma. Discharged home at day 4 of admission, the patient's continued the remaining weeks of her pregnancy uneventfully, until 37 weeks. She delivered her baby vaginally with no further complications during pregnancy or in the postpartum period.

In conclusion, due to the insufficient data in the literature supporting the management of patients with $A M L$, the individualization of the treatment is an essential strategy.

Keywords: "angiomyolipoma" "renal tumor" "pregnancy" "surgery" "embolization".

\section{InTRODUCTION}

1 enal angiomyolipoma (AML) is the most common benign tumor of the kidney. It appears mainly in females during their procreation age and is affected by the hormonal changes occurring during pregnancy. It could be life-threatening when ruptured, leading to severe bleeding.

There are few cases in the literature concerning the optimal management taken in the case of AML, especially during pregnancy.

We, at this moment, are going to describe the evolution of AML during pregnancy in a 32 years old female, trying to maintain a normal renal function and a viable fetus until delivery.

\section{il. Case Presentation}

It is the case of a 32 years-old female who presented at 21 weeks of gestation. She had a one-day history right-sided flank pain, chills, macroscopic hematuria, and vomiting.

Author a $\sigma$ : Department of Obstetrics and Gynecology, Faculty of medicine, Holy Spirit University of Kaslik, Lebanon.

Author $\alpha \sigma \rho$ : Department of Obstetrics and Gynecology, The Centre Hospitalier Universitaire Notre Dame de Secours, Byblos, Lebanon.

Author $\omega$ : Department of Obstetrics and Gynecology, Faculty of Medical sciences, the Lebanese University, Lebanon.

e-mail: jesydarido@hotmail.com
Her medical, surgical, and obstetrical history consisted of kidney stones, one vaginal delivery, and one dilatation and curettage for incomplete abortion. She was on acetylsalicylic acid (ASA) during her current pregnancy.

On examination, she was hemodynamically stable, with no fever. A blood test was ordered and revealed, hemoglobin level at 11.5 (Hematocrit 33.7), White Blood Count (WBC) at 11.9, CRP 3.92, Creatinine 0.48 . Urine analysis showed red blood cells at 80 at WBC at 5. Hepatic panel and electrolytes were within normal levels.

Abdominal examination revealed tenderness on the right groin. The urologist and infectious disease specialists were also in this case. Her pain was relieved by intravenous analgesics and relative bed rest.

The obstetrical ultrasound showed a single intrauterine pregnancy with positive cardiac activity commensurate with the gestational age; however, the renal ultrasound showed the presence of a hyperechogenic vascularized fatty tissue on the right kidney, measuring $7.4 \times 5.1 \times 6.2 \mathrm{cms}$, with minimal pelvicalyceal dilatation. There is no lithiasis or subcapsular hematoma (Image 1). A renal MRI completed the investigations.

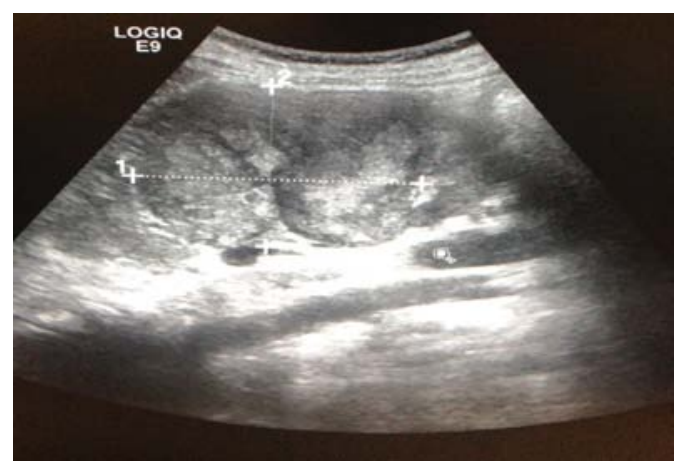

Image 1: Ultrasound of the right kidney, as described above

The $\mathrm{MRI}$ result showed a well-defined, $75 \mathrm{~mm}$, multilocular renal mass occupying the middle segment of the right kidney with an image of a small pelvicalyceal dilatation and an intracavitary hemorrhagic content. Consequently, the MRI report evoked the diagnosis of angiomyolipoma. (Image 2, 3, 4)

\footnotetext{
* Renal pelvis, major and minor calyces
} 


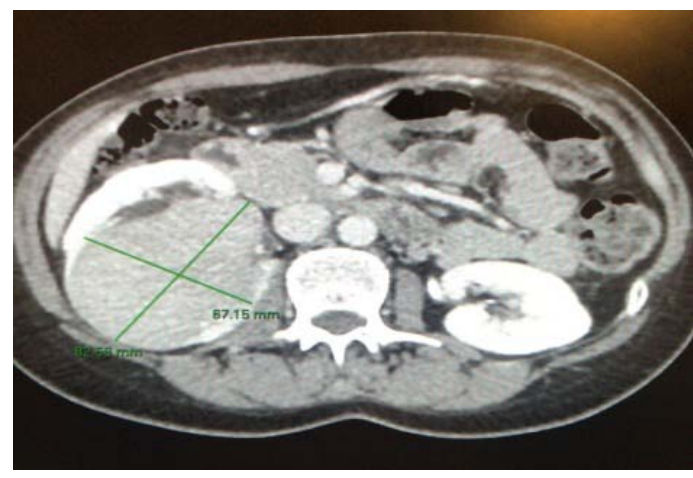

Image 2: A Sagittal MRI cut showing a $75 \mathrm{~mm}$ renal mass

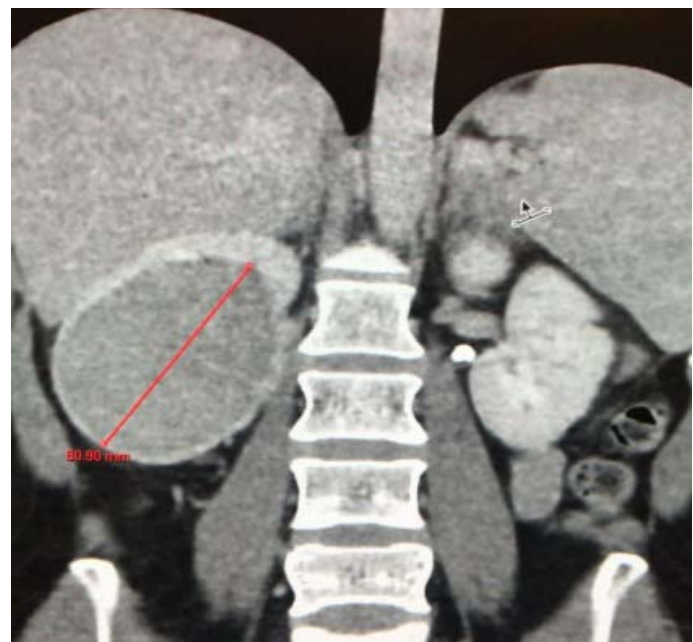

Image 3: A coronal MRI cut showing the well-defined renal mass

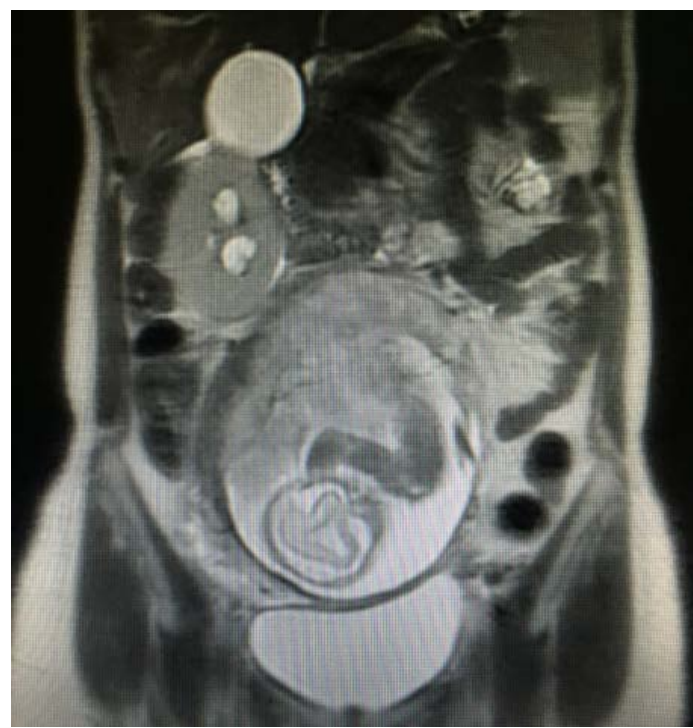

Image 4: A coronal MRI cut showing the gravid uterus, the suspected AML occupying the middle segment of the right kidney with a small pelvicalyceal dilatation and an intracavitary hemorrhagic content

On day 4 of admission, the patient's condition remained stable, with no fever and less pain. Therefore, she was discharged on analgesics with a medical report of her state, so she can rest at home. The remaining weeks of her pregnancy were completely uneventful, and the patient delivered her baby vaginally at 37 weeks with an APGAR of 9/10, weighting $2500 \mathrm{~g}$. There were no further complications during the pregnancy or in the post-partum period.

\section{Discussion}

Angiomyolipoma is the most common benign mesenchymal tumor of the kidney, composed of adipose and vascular tissue in the association of smooth muscle.

Its prevalence varies between 0.12 and 0.14 percent in the general population. There is also a female predominance with a ratio of $4: 1$. Most of the time, it is the Right kidney that is affected [1].

The AML could appear either sporadically or in association with tuberous sclerosis. In the first case, AML is often solitary and accounts for $80 \%$ of the AML. Generally, patients present with a mean age of 43 years old. On the other hand, in $20 \%$ of the cases, AML is associated with tuberous sclerosis. In the latter case, the mean age at the time of diagnosis is 25 to 35 years. The lesions typically exceeds the isolated angiomyolipoma in size, and they are often bilateral and multiple. Angiomyolipoma occurs in $80 \%$ of patients with tuberous sclerosis. Exceptionally, these renal tumors could rupture, leading to massive retroperitoneal hemorrhage and resulting in what we call the Wunderlich syndrome [2].

The classical clinical presentation of $A M L$ is flank pain, palpable mass, nausea, hematuria, and anemia. AML tends to appear during the pregnancy period, due to the hormonal influence of estrogen and progesterone in addition to the increased receptors on the surface of the AML associated with the expansion of the intraabdominal pressure during gestation.

The sonographic features of AML consist of a well-circumscribed and highly echogenic mass because of its high-fat content, multiple nonfatty interfaces, heterogeneous cellular architecture, and numerous vessels. Other renal tumors, such as lipoma, teratoma, Wilms tumor, oncocytoma, and renal cell carcinoma (RCC), may contain fat and can be difficult to be differentiated on imaging studies. A CT scan with thin (less than 5-mm) sectioning is recommended for the confirmation of diagnosis whenever AMLs are suspected [3]. However, MRI does not appear to have an advantage over CT scan, except in pregnancy, and when the intravenous contrast administration is not indicated.

In the case of rupture, hemodynamic stability is of critical importance for the selection of an optimal treatment strategy. In the case of hemodynamically unstable patients, emergent surgery (nephrectomy) or 
arterial embolization (if available) are the main options of treatment [4]. The Embolization consists of an alternative after 12 weeks of gestation with minimal fetal radiation exposure. Concerning the asymptomatic pregnant patients, the conservative approach may be of choice in these cases [5]. As for the definitive treatment, it may be delayed after the delivery.

According to the literature, most of the patients with renal angiomyolipoma, delivered their babies via cesarean section (56\%), whereas only $19 \%$ delivered vaginally (Table 1). However, vaginal delivery is a safe approach for these patients, and the cesarean does not affect the risk of rupture. Consequently, the mode of delivery should be decided based on obstetrical indications only. Vacuum extraction can also be an alternative in order to reduce the time of the second stage of labor.

Seeing that our patient was hemodynamically stable, along with the normal development of her fetus, a multidisciplinary approach decided that the patient proceeds to the term of delivery. She underwent a successful vaginal delivery without complications.

\section{Conclusion}

Due to the insufficient data in the literature supporting the management of patients with $A M L$, the individualization of the treatment is an essential strategy.

We need to have more experience with these strategies and to initiate more studies, so it can be the basis of any recommendation for the optimal treatment method.

\section{Conflict of Interest}

No conflict of interest to declare

Consent and Ethical Approval

Obtained from the patient to publish the case.

Financial Funding

No funding was obtained for this publication.

Table 1: Literature review of angiomyolipoma during pregnancy (Medline database)

\begin{tabular}{|c|c|c|c|c|c|c|c|}
\hline Author & Year & $\begin{array}{c}\text { Maternal } \\
\text { Age }\end{array}$ & GW & $\begin{array}{l}\text { Tumor } \\
\text { size } \\
\text { (cm) }\end{array}$ & Rupture & RA Management & $\begin{array}{c}\text { Pregnancy } \\
\text { Management }\end{array}$ \\
\hline Lee [6] & 1994 & 29 & 27 & NR & Yes & Nephrectomy & Fetal death \\
\hline Yanai [7] & 1996 & NR & 39 & NR & Yes & Embolization & Term delivery \\
\hline Oka [8] & 1999 & 32 & 36 & NR & Yes & Nephrectomy & Term C/S \\
\hline Tanaka [9] & 2001 & 23 & 27 & 7 & Yes & $\begin{array}{c}\text { Conservative + Later } \\
\text { Embolization }\end{array}$ & Vaginal delivery \\
\hline $\begin{array}{c}\text { GimenoArgente } \\
{[10]}\end{array}$ & 2006 & 40 & 33 & NR & Yes & Nephrectomy & CS \\
\hline Raft [11] & 2006 & 40 & 34 & $\overline{N R}$ & Yes & conservative & Preterm C/S \\
\hline Storm [1] & 2006 & 32 & 39 & 8 & Yes & Conservative & Vaginal delivery \\
\hline Koh [12] & 2007 & 31 & 12 & $\mathrm{NR}$ & Yes & Nephrectomy & Term C/S \\
\hline $\begin{array}{c}\text { Illescas Molina } \\
{[13]}\end{array}$ & 2007 & 36 & 28 & NR & Yes & conservative & Term C/S \\
\hline Kontos [14] & 2008 & 28 & 33 & 7 & Yes & Nephrectomy & PreTerm C/S \\
\hline Binkowska [15] & 2009 & 26 & 20 & 17,4 & Yes & Embolization & Term C/S \\
\hline Komeya [16] & 2010 & 39 & 38 & 8 & Yes & Embolization & Term C/S \\
\hline Zapardiel [17] & 2011 & 30 & 35 & 11 & Yes & Embolization & PreTerm C/S \\
\hline Gyimadu [18] & 2011 & 21 & 25 & 11,5 & Yes & $\begin{array}{c}\text { Conservative + Later } \\
\text { Embolization }\end{array}$ & Term C/S \\
\hline Lopater [19] & 2011 & 34 & 30 & 4 & No & Nephrectomy & Term C/S \\
\hline $\begin{array}{c}\text { Govendik Horny } \\
{[20]}\end{array}$ & 2011 & 30 & 20 & 8 & No & Nephrectomy & NR \\
\hline Bolufer [21] & 2012 & 26 & NR & 12 & Yes & Nephrectomy & Vaginal delivery \\
\hline Ferianec [22] & 2013 & 30 & 9 & 21 & Yes & Nephrectomy & Therapeutic Abortion \\
\hline Iruloh [23] & 2013 & 23 & 31 & 12 & Yes & $\begin{array}{c}\text { Embolization } \\
+ \text { Nephrectomy }\end{array}$ & Term C/S \\
\hline Pontis [24] & 2013 & 33 & 34 & 4,8 & Yes & Nephrectomy & Preterm C/S \\
\hline Davis [25] & 2013 & $\mathrm{NR}$ & NR & $\mathrm{NR}$ & NR & NR & NR \\
\hline dos Santos [26] & 2014 & 40 & 18 & 5 & Yes & Conservative & Preterm C/S \\
\hline Preece [27] & 2015 & 45 & 24 & 15 & Yes & $\begin{array}{l}\text { Embolization } \\
+ \text { Nephrectomy }\end{array}$ & Term C/S \\
\hline Bidault [28] & 2015 & 31 & NR & 9 & $\mathrm{No}$ & Nephrectomy & - \\
\hline Cetin [29] & 2015 & 26 & 44 & 11 & No & Nephtectomy & Vaginal delivery \\
\hline
\end{tabular}

NR: Not Reported; GW: Gestational week; RA: Renal Angiomyolipoma; C/S: Caesarean section. 


\section{References Références Referencias}

1. Storm DW, Mowad JJ. Conservative management of a bleeding renal angiomyolipoma in pregnancy. ObstetGynecol 2006; 107:490-2.

2. G. Marino, M. Pedalino, O.G. Di Primio, D. Piras, R. Vella, E. Verces, Wunderlich syndrome. Clinical and therapeutic aspects of a long-term experience, Urologia3 (2010) 193-197.

3. D. Halpenny, A. Snow, G. McNeill, W.C. Torreggiani, The radiological diagnosis and treatment of renal angiomyolipoma-current status, Clin. Radiol. 65 (2)(2010) 99-108.

4. Preece P, Mees B, Norris B, Christie M, Wagner T, Dundee P. Surgical Management of hemorrhaging renal angiomyolipoma in pregnancy. Int $\mathrm{J}$ Surg Case Rep 2015; 7:89-92.

5. J. Shah, J. Jones and M. A. W. Miller, "Selective Embolization of Bleeding Renal Angiomyolipoma in Pregnancy" Journal of the Royal Society of Medicine, Vol. 92, 1999, pp. 414-415.

6. Lee JD et al, angiomyolipoma of the left uterovesical junction J Reprod Med 1994.

7. Yanai $\mathrm{H}$ et al Spontaneous hemorrhage during pregnancy secondary to renal angiomyolipoma Urol Int 1996; 56(3):188-91.

8. Oka $D$ et al Rupture of a renal angiomyolipoma in regnancy: a case report J Gland Biol Neoplasia 1999 Oct; 4(4):415-23.

9. Tanaka $\mathrm{M}$ et al, conservative management and vaginal delivery following ruptured renal angiomyolipoma Obstet Gynecol 2001 Nov; 98:932-3.

10. Gimeno Argente 2006.

11. Raft $J$ et al, renal angiomyolipoma rupture during pregnancy Gynecol Obstet Fertil 2006 Oct; 34(10):917-9.

12. Koh $\mathrm{JL}$ et al, simultaneous cesarean section and radical nephrectomy for angiomyolipoma with spontaneous bleeding during pregnancy: A case report J reprod Med 2007 Apr;52(4):338-40.

13. Illescas Molina $T$ et al, angiomyolipomas, tuberous sclerosis and pregnancy Ginecol Obstet Mex 2009; 77: 380-6.

14. Kontos $S$ et al rupture of renal angiomyolipoma during pregnancy: case report Cases J 2008;1:245

15. Binkowska $M$ et al, embolization of renal angiomyolipoma in pregnancy: case report ginekol pol 2009; 80:449-52.

16. Komeya $\mathrm{M}$ et al rupture of renal angiomyolipoma during pregnancy: a case report Hinyokika Kiyo 2010; 56:261-4.

17. Zapardiel I et al, renal angiolipoma during pregnancy: review of the literature Gynecol Obstet invest 2011; 72:217-9.

18. Gyimadu $A O$ et al, conservative management of a retroperitoneal hemorrhage following a ruptured renal angiolipoma in pregnancy. J obstet Gynaecol res 2011; 37:156-9.

19. Lopater J, Hartung O, Bretelle F, Bastide C. Management of angiomyolipoma vena cava thrombus during pregnancy. Obstet Gynecol 2011; 117:440-3.

20. Govednik-Horny C, Atkins M. Angiomyolipoma with vascular invasion during pregnancy. Ann Vasc Surg 2011; 25:1138.

21. Bolufer E, Lopez-Fontana G, Castillo OA. Robot assisted partial nephrectomy (Da Vinci) in an angiomyolipoma associated to Wünderlich Syndrome. Arch Esp Urol 2012; 65:831-4.

22. Ferianec V, Gabor M, Cano M, Papcun P, Holoman $K$. Severe retroperitoneal haemorrhage in the first trimester of a multiple pregnancy after spontaneous rupture of renal angiomyolipoma. Arch Gynecol Obstet 2013; 288:1193-4.

23. Iruloh C, Keriakos R, Smith DJ, Cleveland T. Renal angiomyolipoma and lymphangioleiomyomatosis in pregnancy. J Obstet Gynaecol 2013; 33:542-6.

24. Pontis A, Piras B, Meloni A, De Lisa A, Melis GB, Angioni $S$. Rupture of renal angiomyolipoma in pregnancy. J Obstet Gynaecol 2013; 33:628-9.

25. Davis NF, Kelly R, Lee MJ, Mohan P. Selective arterial embolisation of bilateral angiomyolipomata in a symptomatic pregnant female. BMJ Case Rep 2013; 2013.

26. Dos Santos MM, Proenca SM, Reis MI, Viana RM, Martins LM, Colaço JM, Nunes FM. Spontaneous rupture of renal angiomyolipoma during pregnancy. Rev Bras Ginecol Obstet 2014; 36:377-380.

27. Preece $P$, Mees $B$, Norris B, Christie M, Wagner T, Dundee $P$. Surgical management of haemorrhaging renal angiomyolipoma in pregnancy. Int $\mathrm{J}$ Surg Case Rep 2015; 7:89-92.

28. Bidault V, Pignot G, Rocher L, Glas L, Patard JJ. Renal angiomyolipoma with inferior vena cava thrombosis during pregnancy. Prog Urol 2015; 25:288-92.

29. Cetin $C$ et al angiomyolipoma during pregnancy: case report and literature review Turk $\mathrm{J}$ obstet Gynecol 2015; 12(02):118-121. 